\title{
CHARACTERIZATION OF PATIENTS UNDER FOLLOW-UP AT THE PREGNANT WOMEN IN RHEUMATOLOGY OUTPATIENT CLINIC OF A RHEUMATOLOGY SERVICE IN THE INTERIOR OF SÃO PAULO
}

Laura Maria Silva de Siqueira1, ${ }^{1, \star}$, Douglas Squizatto Leite ${ }^{1}$, João Flávio Gomes Faria ${ }^{1}$, Daniela Esteves Temporim¹, Matheus Zanata Brufatto ${ }^{1}$, Andrea de Almeida Peduti Batista ${ }^{1}$, Henrique Pereira Sampaio ${ }^{1}$, Luiz Eduardo Valente ${ }^{1}$, Sula Glaucia Lage Drumond Pacheco ${ }^{1}$, Sean Hideo Shirata Lanças ${ }^{1}$

1.Universidade Estadual Paulista "Júlio de Mesquita Filho", Botucatu (SP), Brazil.

*Corresponding author: mss.laura@yahoo.com

\section{BACKGROUND}

The management of pregnancy in patients with immune-mediated rheumatic diseases differs from usual, therefore rheumatologists should discuss, advise and monitor the pregnancy to optimize severe adverse maternal or fetal outcomes. We present the profile of patients followed at the Pregnant Women in Rheumatology outpatient clinic of a reference university hospital in the countryside of São Paulo state.

\section{METHODS}

A review of the medical records of all consecutive patients treated at the Pregnant Women in Rheumatology outpatient clinic between 2018 and 2021 was carried out. Sociodemographic, clinical, laboratory, drug therapy, gynecological, and follow-up data were collected, rheumatological and gynecological complications in the period of gestation.

\section{RESULTS}

Forty-nine patients were identified, with 3 patients being followed up in two consecutive pregnancies. Of these, 5 patients were discharged due to diagnostic exclusion. The sociodemographic results are described in Table 1, the distribution of rheumatologic diagnoses in Figure 1, rheumatologic and gynecologic complications, and gestational outcome are described in Table 2. The clinic was created in 2004 and brings together cases from the Cuesta and Vale do Jurumirim pole of the DRS VI in São Paulo, in addition to other regions.

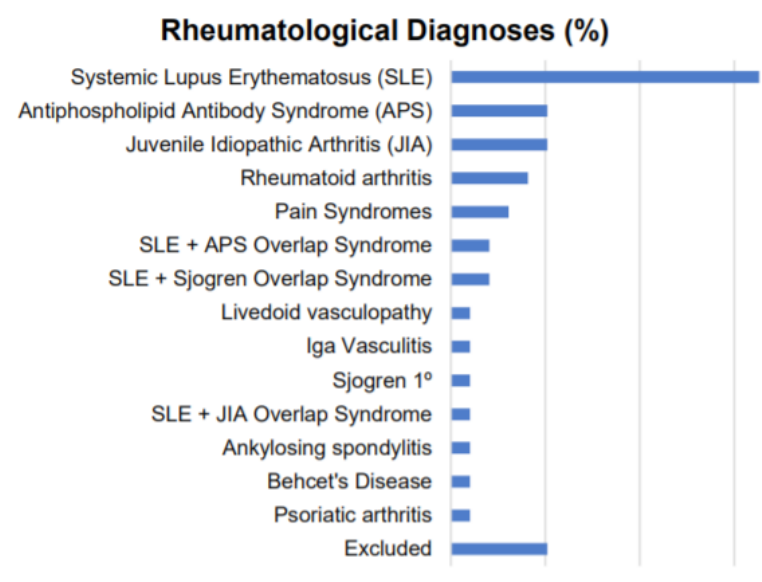

Figure 1. Distribution according to etiological diagnosis. 
Table 1. Sociodemographic profile.

\begin{tabular}{|c|c|c|}
\hline \multicolumn{2}{|r|}{ Parameters } & $\mathrm{N}$ \\
\hline \multicolumn{2}{|r|}{ Age (years) } & $29.47 \pm 6.81$ \\
\hline \multirow{3}{*}{ Skin color } & White & $38(77.55 \%)$ \\
\hline & Black & $2(4.08 \%)$ \\
\hline & Brown & $7(14.29 \%)$ \\
\hline \multirow{3}{*}{ Marital status } & Married & $18(36.73 \%)$ \\
\hline & Single & $10(20.41 \%)$ \\
\hline & Stable union & $21(42.86 \%)$ \\
\hline \multirow{6}{*}{ Education } & Incomplete elementary school & $3(6.12 \%)$ \\
\hline & Incomplete high school & $9(18.37 \%)$ \\
\hline & Complete high school & $24(48.98 \%)$ \\
\hline & Incomplete higher education & $3(6.12 \%)$ \\
\hline & Complete higher education & $8(16.33 \%)$ \\
\hline & Master's or Doctorate & $2(4.08 \%)$ \\
\hline \multicolumn{2}{|c|}{ Number of assistances } & $5.04 \pm 2.94$ \\
\hline \multicolumn{2}{|r|}{ Comorbidities } & $28(57.14 \%)$ \\
\hline \multicolumn{2}{|r|}{ Smoking } & $4(8.16 \%)$ \\
\hline
\end{tabular}

Table 2. Initial profile and clinical and obstetric outcomes of patients followed in the period.

\begin{tabular}{|c|c|c|}
\hline \multicolumn{2}{|c|}{ Outcomes } & $\mathrm{n}(\%)$ \\
\hline \multicolumn{2}{|c|}{ Disease activity early pregnancy } & $11(22.45 \%)$ \\
\hline \multicolumn{2}{|c|}{ Adhesion } & $35(71.43 \%)$ \\
\hline \multicolumn{2}{|c|}{ Previous obstetric morbidity } & $22(44.90 \%)$ \\
\hline \multicolumn{2}{|c|}{ Rheumatological Intercurrences } & $16(32.65 \%)$ \\
\hline \multicolumn{2}{|c|}{ Gynecological Intercurrences } & $30(61.22 \%)$ \\
\hline \multicolumn{2}{|c|}{ Medicines during pregnancy: } & - \\
\hline \multicolumn{2}{|c|}{ Immunosuppressant } & $4(8.16 \%)$ \\
\hline \multicolumn{2}{|c|}{ Corticosteroid } & $13(26.53 \%)$ \\
\hline \multicolumn{2}{|c|}{ Hydroxychloroquine } & $29(59.18 \%)$ \\
\hline \multicolumn{2}{|c|}{ Enoxaparin } & $6(12.24 \%)$ \\
\hline \multicolumn{2}{|c|}{ Acetylsalicylic acid } & $32(65.31 \%)$ \\
\hline \multicolumn{2}{|c|}{ Infiltration } & $5(10.20 \%)$ \\
\hline \multirow{4}{*}{ Gestation time } & $<20$ weeks & $1(2.04 \%)$ \\
\hline & 20 to 37 weeks & $13(26.53 \%)$ \\
\hline & 37 to 40 weeks & $24(48.98 \%)$ \\
\hline & $>40$ weeks & $2(4.08 \%)$ \\
\hline \multirow{3}{*}{ Delivery } & Normal & $18(36.73 \%)$ \\
\hline & Cesarean & $21(42.86 \%)$ \\
\hline & Childbirth in progress & $1(2.04 \%)$ \\
\hline \multirow{2}{*}{ Newborn Alive } & Yes & $39(79.59 \%)$ \\
\hline & No & $1(2.04 \%)$ \\
\hline
\end{tabular}




\section{CONCLUSION}

We present the initial characterization of the patients who followed the Pregnant Women in Rheumatology clinic, with good results and management in the period. Such data will serve as a basis for future analysis and studies.

\section{KEYWORDS}

Pregnant women in rheumatology, Gynecological complications, Rheumatological complications. 